\title{
Identifying the multidimensional poor in developed countries using relative thresholds. \\ An application to Spanish data
}

\begin{abstract}
In order to contribute to providing a methodology to ensure objectivity and transparency in the measurement of multidimensional poverty, this paper proposes a new threshold for the identification of the multidimensional poor which is also applicable to each of the dimensions of poverty, suitable for identifying the severely poor in developed countries. This new methodology is applied to analyse the evolution of material deprivation in Spain during the period of economic crisis, comparing the results with those obtained using other traditional approaches.
\end{abstract}

Key words: Multidimensional poverty, counting approach, poverty lines, Spain. 


\section{Introduction}

In recent decades, a broad academic and institutional consensus has emerged regarding the need to study poverty as a multidimensional phenomenon, integrating material deprivation and social exclusion concerns (Sen 1985) in aggregated indicators. However, despite this consensus, there are still many methodological issues when measuring multidimensional poverty that are imbued with subjectivity and a lack of transparency. Among other negative outcomes, this prevents international comparisons from being conducted. In order to construct an objective methodology for measuring severe multidimensional poverty and deprivation, in this paper, a new relative threshold for identifying multidimensional poor or deprived segments is proposed especially suited for developed countries. Using this new threshold, we have quantified and analysed the evolution of material deprivation in Spain during the economic crisis, comparing the results with those obtained using absolute and subjective thresholds proposed in the literature by other authors.

Atkinson et al. (2002) distinguish two different methods to summarise the multidimensional information ${ }^{1}$. The first is to build simple poverty indicators for each dimension and then add in a synthetic indicator. Prominent examples of synthetic indicators are the Human Development Index or the Human Poverty Index. This approach is based on the marginal distributions of each dimension. The second form of aggregation builds on the joint distribution of the dimensions in order to quantify the level of poverty. In this approach, a set of highly empirical contributions summarises information of all the dimensions in a single variable using multivariate statistical methods (Townsend 1979; Desai and Shah 1988; Guio et al. 2009; Ayala, et al. 2011).

Another set of contributions, which take into account the joint distribution of the poverty dimensions, has focused on the proposal of poverty indices that combine information on several dimensions (Bourguignon and Chakravarty 2003; Lemmi and Betti 2006; Alkire and Foster 2007 and 2011a). These contributions include those based on the counting approach, introduced by Atkinson (2003) and are suitable for both qualitative and quantitative variables. This approach, which concentrates on counting the number of dimensions in which people suffer poverty or deprivation, helps overcome the disadvantages of most of the measures that can only be calculated for quantitative variables.

Within the framework of the counting approach, Alkire and Foster (2007 and 2011a) propose a methodology, connected with the one-dimensional analysis of the phenomenon, that relies on a method for identifying the poor or deprived and another for aggregating the data and summarising the information on multiple dimensions in one scalar. The identification method, known as dual cutoff, can be based on two kinds of thresholds. The first cutoff is used to

\footnotetext{
${ }^{1} \mathrm{~A}$ review of the main methodologies to measure multidimensional poverty may be found in Silber (2007).
} 
identify who are deprived in each dimension and the second determines whether a person is poor or deprived from the multidimensional point of view. There is no unique criterion for determining this second threshold. Different options ranging from the union (any person deprived in at least one dimension is considered to be multidimensionally poor) to the intersection approaches (multidimensional poor only refers to people who are deprived in every dimension) could be adopted. Between these two extremes, the vast majority of authors have used absolute lines and subjective criteria for determining the second threshold. As Alkire and Foster (2011a) point out, the establishment of this second cutoff has hardly been addressed in the literature. The main goal of this paper is to propose a method to establish this second cut off by incorporating the relative aspect of poverty.

In the context of monetary poverty measurement, absolute poverty lines have been primarily used by developing countries (Ravallion and Chen 2011), where it makes sense to study the population which cannot access a set of basic goods and services. As societies become more advanced this analysis becomes meaningless, since the improvement process in these societies enables individuals to reach a higher level of welfare and the headcount of absolute poverty would stand at almost zero. However, this does not mean that there are no people who are living in a disadvantaged position compared to the rest of the population.

Generally speaking the idea behind the measurement of poverty in relative terms is to characterise the typical behavior of the population (usually expressed by the mean or median of the distribution of income) and to study those who display a conduct that is divergent to this behavior ${ }^{2}$.

This relative notion can also be applied to the multidimensional poverty approach, incorporating additional indicators, apart from income, for describing the standard of living and then counting people that do not reach this reference level that enables them to participate in the normal activities of their society. As Townsend (1979, p. 915) points out, poverty is a form of relative deprivation: "the absence or inadequacy of those diets, amenities, standards, services and activities which are common or customary in society".

Within the context of the European Union, which is the area in which the empirical application of this study is presented, the use of a relative perspective to measure poverty or deprivation has been justified in the following terms: "An absolute notion is considered less relevant for the EU for two basic reasons. First the challenge for Europe is to make the whole population share the benefits of high average prosperity and not to reach basic standards of living as in developed parts of the world. Secondly, what is regarded as minimal acceptable living standards depends

\footnotetext{
${ }^{2}$ The use of absolute or relative lines leads to very different results as illustrated by Garroway and De La Iglesia (2012).
} 
largely on the general level of social and economic development, which tend to vary considerably across countries" (European Commission 2004, p. 13).

In order to introduce the above-mentioned ideas in a mathematical expression, first, the normal behaviour of the society must be quantified, and second, we must establish a criterion for determining the people that diverge from this behaviour. Statistically, the normal behaviour of a distribution can be characterised by different measures of central tendency, and abnormal behaviour through the identification of outliers.

Specifically, the proposal developed here uses relative multidimensional poverty thresholds based on statistical criteria for detecting outliers. This methodology overcomes the subjectivity of the usual methods, taking into account the relative nature of the phenomenon, and, at the same time, brings together two virtues: transparency and simplicity. Atkinson (1998) attributed these characteristics to the thresholds based on a percentage of the mean or median income in the case of monetary poverty.

The implications of using the concept of social exclusion associated with relative poverty lines are particularly relevant in the dynamic analysis since the relative threshold is automatically updated, that is to say, it varies systematically with objective and verifiable data. This relative threshold is particularly suitable for the study of poverty in developed countries, where, as we have said, the justification for using absolute thresholds is weaker. In this context, the threshold may be applied for determining the extent of severe material deprivation by identifying those affected by social exclusion.

The structure of this paper is as follows. The methodology is presented in the second section. In the third section, the data used and some relevant methodological choices in the study will be described. In the fourth section, the results obtained in the analysis of material deprivation in Spain between 2008 and 2012, using the new poverty line, will be presented. Finally, the fifth section concludes the paper.

\section{Methodology}

Within the different approaches developed to aggregate and summarise information on multidimensional poverty, we have adopted the methodology of Alkire and Foster (2007, 2011a) based on the counting approach (Atkinson 2003). There are three main aspects that determine this methodology: The selection of the dimensions of poverty, the identification of the poor -in each dimension and the criteria for distinguishing between the multidimensional poor and non-poor- and, finally, the aggregation of information through a poverty index.

On the selection of dimensions, Sen (1985), the main precursor of multidimensional poverty analysis, considered that the determining dimensions of poverty depend on the geographic, economic, cultural and temporal context. Moreover, this author argued that there is no set list of 
dimensions. In the empirical part of this study, the indicators considered, as listed below, are those included in EU-SILC to estimate the material deprivation indicators for EU countries ${ }^{3}$.

The identification of the poor is based on a dual cutoff method. The first cutoff, called the deprivation cutoff, determines who is disadvantaged in each dimension. Let $X_{\mathrm{ij}}$ be the quantity of attribute $j$ possessed by person $\mathrm{i}$, with $\mathrm{j}=1 \ldots D$, and let $Z_{\mathrm{j}}$ be the deprivation cutoff of dimension $j$. Then, person $i$ is deprived in dimension $j$ if $X_{\mathrm{ij}}<Z_{\mathrm{j}}$. Alkire and Foster (2011a) point out that the specific choice of $Z_{\mathrm{j}}$ is somewhat arbitrary, but selecting levels for these individual cutoffs should not be a difficult exercise.

The second cutoff $(k)$, which we call the multidimensional threshold or multidimensional poverty line or poverty cutoff, is based on a new variable, $P M$, defined as the weighted sum of the dimensions in which a person is deprived, that is,

$$
P M_{i}=\sum_{j=1}^{D} w_{j} I_{\left\{X_{i j}<Z_{j}\right\}} \text { for } i=1 \ldots n
$$

where $I_{\{B\}}$ denotes the indicator function on a set $B, w_{\mathrm{j}}$ is the weight given to each indicator and $n$ is the population size. The weights will be standardised so that their sum is equal to the number of indicators $D$. Note that if all weights were equal to one, $P M$ will be the number of deprivations suffered by a person. $P M$ takes values between 0 and $D$ : the value 0 is associated to a person who is not deprived in any attribute and the value $D$ is associated with a person who is deprived in all dimensions. There has been much discussion about the choice of weights for the different attributes: see, for example, Decanq and Lugo (2008). In our case, the weights depend, negatively, on the proportion of the community who are deprived (see, Desai and Shah 1988).

The multidimensional poverty line will allow us to classify people as being multidimensionally poor or not depending on the value of the $P M$ in each person. So, person $i$ is multidimensionally poor if the $P M$ value is at least equal to the poverty cutoff $\left(P M_{i} \geq k\right)$; otherwise, if the $P M$ value falls below the poverty cutoff $\left(P M_{i}<k\right)$ then person $i$ is not multidimensionally poor.

With regard to the second cutoff, most authors perform a sensitivity analysis, although a specific line of reference is used in order to draw some conclusions on the evolution of the main indicators of poverty and deprivation. There are a wide variety of proposals in the literature with regard to this reference line and a clear absence of an explicit formulation or a methodological proposal for choosing a value between the union and the intersection criteria. Thus, Gordon et al. (2003) use as the poverty line one fourth of the weighted dimensions while Battiston et al. (2013), Alkire and Seth (2013), Alkire and Santos (2014), Alkire and Seth (2015) use one-third

\footnotetext{
${ }^{3}$ In order to analyse the performance of the threshold proposed using income as one of the dimensions of the poverty indicator, the threshold has also been used to analyse multidimensional poverty with data from Spain using the dimensions included in the AROPE rate (At risk of poverty or social exclusion) including monetary poverty. The results reveal the proper functioning of the threshold and are available to readers on request in an annex.
} 
of weighted dimensions. Foster (2007), Ura et al. (2012) and Batana (2013) set the threshold at $50 \%$ of the dimensions. In a European context, more recently, Alkire et al. (2014) set two reference thresholds: two or more dimensions and three or more dimensions or their equivalents in the weighted indicators. In all these studies, the authors used a normative approach when setting the threshold, which leads to the absence of a single and explicit criterion to set the poverty line, thus the choice of the poverty line can be a policy tool (Alkire et al. 2015). Furthermore, in all cases, the proposals ignore the relative nature of poverty and its connection to the notion of social exclusion ${ }^{4}$ experienced by the group of multidimensional poor who do not achieve an average standard of living (Atkinson 1998), which also changes over time and across the different societies studied ${ }^{5}$.

Our proposal for establishing the second threshold is based on statistical criteria for the detection of outliers in the empirical distribution of $P M$. One advantage of setting the multidimensional threshold according to the $P M$ distribution is that it captures the relative nature of poverty (Townsend 1979), an aspect that some authors have highlighted as a key part of the social exclusion concept (Sen 2000 and 2006; Atkinson and Marlier 2010). Furthermore, our poverty cutoff implies an acceptable judgement with which to evaluate poverty: a person with a greater multiplicity of deprivations (far exceeding the rest) is given higher priority than someone with a number of deprivations similar to the majority of society. Thus our threshold is particularly suitable for identifying people in situations of severe-poverty.

Relatively speaking, a person can be considered as poor if the value of $P M$ is far from the all other values in the empirical distribution. In this sense, we can establish that the outliers correspond to poor or excluded people. Most of the criteria used in the detection of outliers (Barnnett and Lewis 1994 and Peña 2002) are based on distributions that are continuous. The $P M$ variable is not continuous by nature, but could be treated as such if the number of values between 0 and $D$ is large, as is the case when the number of dimensions is high and each one has a different weight.

In particular, we propose the use of the criteria underlying the construction of box-and-whisker plot (hereafter, boxplots). Boxplots are a graphic way of displaying data that consists of a box extending from the first quartile $\left(Q_{1}\right)$ to the third quartile $\left(Q_{3}\right)$, a line at the median and whiskers extending from the first and third quartiles to the extreme data within the inner fences determined by a lower limit, $L_{L}=Q_{1, P M}-1,5\left(Q_{3, P M}-Q_{1, P M}\right)$, and an upper limit, $L_{U}=$

\footnotetext{
${ }^{4}$ It should be noted that the concept of social exclusion has had great relevance in the European Union institutional framework, where the characterisation of poverty as a multidimensional phenomenon integrates aspects of social exclusion and material deprivation.

${ }^{5}$ In this sense, Atkinson (1998) defines excluded people as those who have been removed from the involvement in the normal activities of the society in which they live, connecting with Sen's approach on the individual lacking the basic capabilities required to obtain the basic functionings in a society.
} 
$Q_{3, P M}+1,5\left(Q_{3, P M}-Q_{1, P M}\right)$, respectively. The interquartile range $\left(I Q R=Q_{3, P M}-Q_{1, P M}\right)$ is simply the width of the box in the boxplot, that is used as a measure of how spread out the values are. Data outside the inner fences are considered outliers (Tukey 1977). This graphical representation of the variable distribution enables us to study outlying observations, with few assumptions about the shape of the distribution of the variable.

Thus, the relative multidimensional threshold $k_{r}$ would be:

$$
k_{r}=Q_{3, P M}+1,5\left(Q_{3, P M}-Q_{1, P M}\right) \text {, subject to: } 0<k_{r} \leq D .
$$

Therefore, this threshold will be used to detect excluded individuals who are far from the central value, corresponding to outliers of the distribution because they lie outside the expected range.

Other values could be given for the constant that multiplies the interquartile range in order to adjust the poverty line for each case of study. In this paper, we use the value 1.5 since we want to identify the poor in extreme situations of social exclusion equivalent to the concept of outliers.

Consequently, a person with a value of the $P M$ variable above this threshold is classified as being multidimensionally poor, behaving atypically to the general behaviour of the individuals belonging to the population. So, we have objectively defined a threshold, obtained by way of a clear statistical interpretation, sensitive to the changes in the empirical distribution of the number of deprivations. The procedure is simple and intuitive and can help practitioners in the analysis and understanding of poverty and deprivation.

Thanks to its relative nature, the new threshold will be automatically adjusted. Moreover, since its construction is based on percentiles and on the inter-quartile range, as are location and dispersion measures, the threshold will be more robust for asymmetric distributions -usually observed for $P M$ - than other statistical measures such the mean or the standard deviation.

Another advantage of this approach is that it could also be applied when setting thresholds for individual poverty indicators, when the non-qualitative nature of indicators allows their use.

The proposed threshold has, however, disadvantages inherent in relative poverty lines. These include the possibility that in some cases the threshold is not able to detect a percentage excluded in some distributions with no outliers. This is the reason why the threshold is presented within a specific context with the objective of detecting severe social exclusion related to severe poverty or deprivation ${ }^{6}$.

\footnotetext{
${ }^{6}$ Sen (1983, p. 159) argues that "If there is starvation and hunger, then -no matter what the relative picture looks like- there clearly is poverty. In this sense the relative picture -if relevant- has to take a back seat behind the possibly dominating absolute consideration."
} 
Atkinson (2003) and Alkire and Foster (2011a) recommend using different multidimensional lines in order to check robustness. In this respect, the results regarding poverty orderings of Lasso de la Vega (2010), Alkire and Foster (2011a) and Duclos et al. (2006) could be useful. However, the specification of a multidimensional poverty line with significant meaning may be necessary to draw unambiguous conclusions about the level of poverty and to characterise specific segments of the population.

Once the multidimensional poor are identified using the proposed criterion, different measures can be used to quantify the level of multidimensional poverty or deprivation. Among the measures proposed by Alkire and Foster (2007 and 2011a), some indices are more suitable because they can be obtained for both quantitative and qualitative dimensions ${ }^{7}$. Of these, in the empirical analysis, we will use first the percentage of the population who are poor, the headcount ratio $(H)$. This measure seeks to reflect the incidence of poverty, but ignores its intensity. This is because when the number of deprivations of a poor person increases, this indicator will not experience any changes. To overcome this shortcoming, we will use the adjusted headcount ratio $\left(M_{0}\right)$, introduced by Alkire and Foster (2007 and 2011a), that reflects both the incidence and intensity of poverty ${ }^{8}$. The adjusted headcount ratio is defined as:

$$
M_{0}=\frac{\sum_{i=1}^{n} P M_{i} I_{\left\{P M_{i} \geq k\right\}}}{n D}
$$

Thus it is the sum of $P M$ among the poor people divided by the sum of $P M$ if all people were deprived in all dimensions. $M_{0}$ could be also calculated by multiplying the proportion of people who are poor by the average deprivation share across the poor?. The adjusted headcount ratio can be decomposed into population subgroups and dimensions, which allows us to analyse the specific contributions of dimensions and regions to overall poverty ${ }^{10}$.

\footnotetext{
${ }^{7}$ These poverty indices are an extension of the family proposed by Foster et al. (1984) in the monetary poverty context.

${ }^{8}$ The poverty intensity concept used in this paper is drawn from the Alkire and Foster methodology and refers to the number of deprivations experienced by the poor (Alkire and Foster 2011b). This concept differs from that used in the one-dimensional analysis of poverty in which the intensity of poverty is measured through a function that summarises the distances from the poverty line to the income of the poor (Jenkins and Lambert 1997).

${ }^{9}$ In this sense, this measure overcomes one of the shortcomings of the multidimensional poverty headcount $(H)$ since it does not increase when the number of deprivations that poor people have increases.

${ }^{10}$ Other properties of $M_{0}$ could be found in Alkire and Foster (2011a).
} 
3. Multidimensional deprivation and poverty in Spain using relative poverty lines (20082012)

The purpose of this section is to illustrate the performance of the new threshold applied to the calculation of material deprivation measures in Spain using the methodology of multidimensional poverty ${ }^{11}$. The data are drawn from the EU-Statistics on Income and Living Conditions (EU-SILC) instrument, which is the EU reference source for comparative statistics on income distribution and social inclusion at the European level. We have based our analysis on the surveys conducted in 2008 and 2012, in order to evaluate the changes experienced in material deprivation and multidimensional poverty during the years of economic crisis.

In order to adopt a broader perspective of social inclusion we have studied the characteristics related to material deprivation in Spain ${ }^{12}$. The material deprivation rate is an indicator in EUSILC that expresses the inability to afford some items considered by most people to be desirable or even necessary to lead an adequate life. Therefore, material deprivation rates complement the social exclusion picture by providing an estimate of the proportion of people whose living conditions are severely affected by a lack of resources. We will use our proposal of relative and objective threshold as opposed to the absolute and subjective line adopted by the EU Social Protection committee. In order to measure deprivation, the EU Social Protection Committee's line establishes the percentage of the population that cannot afford at least four of the following nine items: 1) (arrears on) mortgage or rent payments, utility bills, hire purchase instalments or other loan payments; 2) one week's annual holiday away from home; 3) a meal with meat, chicken, fish (or vegetarian equivalent) every second day; 4) unexpected financial expenses; 5) a telephone (including mobile phone); 6) a colour TV; 7) a washing machine; 8) a car and 9) heating to keep the home adequately warm.

Table 1 shows the estimates of the multidimensional poverty head count $(H)$ and the adjusted head count ratio $\left(M_{0}\right)$ for Spain, using the threshold based on the boxplots and also other poverty lines proposed in the literature. Standard errors of poverty measures are in parentheses.

\section{TABLE 1 ABOUT HERE}

\footnotetext{
${ }^{11}$ In order to check the validity of the proposed threshold, using UE-SILC samples of the twenty-eight EU countries, from 2005 to 2013, we have tested whether PM distributions without outliers could exist. The analysis of all the PM distributions reveals that all PM distributions have outliers.

${ }^{12}$ This work is part of a broad line of research on multidimensional poverty that utilises the EU-SILC for Spain and the other countries of the European Union and that, despite the diversity of approaches adopted, allows for some international comparisons of poverty multidimensional results. Among the most recent studies in this line of research, we can find those of Bárcena et al. (2014), Alkire et al. (2014), Whelan and Maître (2012, 2013) and the report of the Consejo Económico y Social (2013) which considers all available waves of the survey.
} 
The overall poverty increase in the Spanish population led to an increase of 0.6 in the deprivation threshold in 2012, calculated with the expression in equation (2). So, in 2008, a person is considered to be materially deprived when the value of his/her $P M$ variable is equal to or greater than 2.6 while in 2012 this threshold rises to 3.2, adjusting automatically to the changes experienced in the deprivation data. Using both thresholds, in the whole country a significant increase in all the analysed deprivation indicators can be observed. Therefore, if the percentage of materially deprived people was $3.2 \%$ in 2008 , this figure rose to $5.8 \%$ in 2012 , representing an increase in the number of materially deprived people of 1,265,522.

Our results contrast with those obtained using some of the normative lines proposed in the economic literature (Table 1). Therefore, considering the union criterion, the percentage of extreme poverty or deprivation would be $43.7 \%$ and $55.9 \%$ respectively for 2008 and 2012 , obviously generating an upward biased estimation. The choice of a threshold equivalent to a number greater than half of the weighted dimensions would lead to the opposite conclusion, that is, extremely low rates of material deprivation, less than $1 \%$. The conclusions obtained using the adjusted headcount ratio would be very similar.

Nevertheless, the poverty indicators estimated using the proposed relative thresholds are close to those obtained for some normative lines used in several studies (Battiston et al. 2013; Alkire and Seth 2013; Alkire and Santos 2014 and Alkire and Seth 2015) in which the poor are those who lack the minimum standards agreed at an international level. However, the threshold proposed changes between 2008 and 2012 to adapt to the distributions of weighted indicators. This means that the levels and variations of poverty indicators between the two years considered are different from those obtained using fixed thresholds. Furthermore, this relative cutoff has full meaning because it allows those people who deviate from the standard behaviour of the population to be identifyied as poor. In this sense, our proposal is not a value used to reach an accepted level of poverty but it is drawn from analysing the characteristics of a specific society.

In this application, we use the relative threshold to identify severe material deprivation. In the European context, the threshold used by EUROSTAT is a fixed value of 4 out of 9 of unweighted indicators and, as in the studies mentioned above, is not based on the specific features of the population. In any case, the percentages of the severely materially deprived obtained by Eurostat for 2008 and 2012 (3.6\% and 5.8\% respectively) are close to those calculated using a relative threshold to estimate severe material deprivation rates indicating that the proposed threshold achieved an adequate approximation to the concept to be quantified.

Alternatively, our results have an objective statistical interpretation based on a relative poverty threshold, which has been automatically adjusted to the variation of $P M$ data from 2008 to 2012 , as shown in Figure 1. So the proposed threshold incorporates changes in location (central 
values) and changes in the statistical dispersion (interquartile range) observed in the right tail of the $P M$ distribution. Those people who suffer a greater number of deprivations are located in this tail.

\section{FIGURE 1 ABOUT HERE}

Table 2 shows our estimates of the multidimensional poverty head count $(H)$, the adjusted head count ratio for Spain and its regions $\left(M_{0}\right)$ and the decomposition of the national adjusted head count ratio by region $\left(\% M_{0}\right)$. Standard errors of poverty measures are in parentheses.

\section{TABLE 2 ABOUT HERE}

From the regional results presented in Table 2, it follows that the regions which present the highest levels of material deprivation, according to $H$ and $M_{0}$ indicators, are Andalusia, the Balearic Islands and Murcia in the two years considered.

The regions with the lowest levels in both deprivation measures in 2008 and 2012 are Cantabria, Asturias and Castile and Leon.

All regions show higher poverty indicators in 2012 than in 2008, although some regions improved their relative position. This is the case of the Basque Country which holds the best position in 2012. Catalonia displays the most striking behaviour with the largest increase in the two measures of material deprivation.

Decomposing the $M_{0}$ into the different subpopulations allows us to establish the contribution of each region to poverty in Spain. The contributions are determined by the specific value of $\mathrm{M}_{0}$ and the population weight of each region. The contributions to the adjusted head count ratio $\left(M_{0}\right)$ for Spain, presented in Table 2 (columns 4 and 7) show that Andalusia is the region that accounts for the greatest proportion of total poverty in 2008 and 2012, since it is the region with the highest population weight and the higher specific value of $\mathrm{M}_{0}$. This contribution decreases in 2012 by more than eight points. Again, the case of Catalonia is exceptional, as it increases its contribution to the $\mathrm{M}_{0}$ indicator by about seven percentage points. The five regions with the best situation in each indicator in 2008 are the same as those in 2012, exchanging their positions with one another during the time period between the two years. Therefore, large variations are not observed in the regional contributions to the indicators of multidimensional poverty in 2008 and 2012. As previously mentioned, these results reveal that the spatial distribution of multidimensional poverty in Spain between 2008 and 2012 has in general remained unchanged, as we can observe in Figure 2.

FIGURE 2 ABOUT HERE 


\section{Conclusions}

This study proposes and applies a new method for setting a threshold on multidimensional poverty based on statistical criteria used in determining outliers suitable for identifying the severely multidimensional poor in developed countries. This alternative, related to the concept of social exclusion and not used in other studies to date, provides an objective method for determining a relative threshold that automatically adjusts to changes in the population distribution of the number of deprivations. Therefore, the poverty line will change over time and consistently with the cross-sectional variation registered among countries.

This methodology overcomes the subjectivity of the traditional methods and it brings together two virtues: transparency and simplicity. Furthermore, as we have mentioned, this relative threshold is particularly suitable for the study of poverty in developed countries, as the justification of absolute thresholds is weaker in cross section and longitudinal comparisons. Moreover, the empirical application confirms that the threshold based on boxplots is suitable for measuring extreme poverty compared to other thresholds proposed by some authors in the literature.

From an empirical point of view, this study supports the conclusion that between 2008 and 2012 a general deterioration of the level of multidimensional poverty in Spain and its regions took place. This has been demonstrated by applying the relative threshold proposed by the study. If we analyse the relative position of the regions, we can observe that the spatial distribution of multidimensional poverty and material deprivation in Spain has remained mostly unchanged during the years of economic crisis.

\section{References}

Alkire, S., Apablaza, M., \& Jung, E. (2014). "Multidimensional Poverty Measurement for EUSILC Countries". OPHI Research in Progress 36c, Oxford University

Alkire, S., \& Foster, J. (2007). Counting and Multidimensional Poverty Measures. OPHI Working Paper, $n^{\circ} 7$.

Alkire, S., \& Foster, J. (2011a). Counting and Multidimensional Poverty Measurement. Journal of Public Economics, 95(7-8), 476-487.

Alkire, S., \& Foster, J. (2011b). Understandings and misunderstandings of multidimensional poverty measurement. Journal of Economic Inequality, 9 (2), 289-314.

Alkire, S., Foster, J., Seth, S., Santos, E., Roche, J.M., \& Ballon, P.. (2015). Multidimensional Poverty Measurement and Analysis, Oxford: Oxford University Press. 
Alkire, S., \& Santos, M.E. (2014). Measuring Acute Poverty in the Developing World: Robustness and Scope of the Multidimensional Poverty Index. World Development, 59, 251274.

Alkire, S., \& Seth, S. (2013). Selecting a targeting method to identify BPL households in India. Social Indicators Research, 112 (2), 417-446.

Alkire, S., \& Seth, S. (2015). Multidimensional Poverty Reduction in India between 1999 and 2006: Where and How?. World Development, 72 (C), 93-108.

Atkinson, A.B. (1998). Poverty in Europe, Oxford, Wiley and Blackwell.

Atkinson, T., Cantillon, B., Marlier, E., \& Nolan, B. (2002). Social Indicators: The EU and Social Inclusion, Oxford: Oxford University Press.

Atkinson, A. B. (2003). Multidimensional deprivation. Contrasting social welfare and counting approaches. Journal of Economic Inequality, 1, 51-65.

Atkinson, A.B., \& Marlier, E. (2010). Income and living conditions in Europe. Luxembourg: European Commission, Eurostat Statistical Books.

Ayala, L., Jurado, A., \& Pérez-Mayo, J. (2011). Income Poverty and Multidimensional Deprivation: Lessons from Cross-regional Analysis. Review of Income and Wealth, 57, 4060.

Bárcena, E., Lacomba, B., Moro-Egido, A. I. \& Pérez-Moreno, S. (2014). Country Differences in Material Deprivation in Europe. Review of Income and Wealth, 60 (4), 802-820.

Barnett, V., \& Lewis, T. (1994). Outliers in statistical data, John Wiley \& Sons.

Batana, Y. (2013). Multidimensional Measurement of Poverty Among Women in Sub-Saharan Africa. Social Indicators Research, 112(2), 337-362.

Battiston, D., Cruces, G., López-Calva, L. F., Lugo, M. A. \& Santos, M. E. (2013). Income and Beyond: Multidimensional Poverty in Six Latin American Countries. Social Indicators Research, 112(2): 291-314.

Bourguignon, F., \& Chakravarty, S., (2003). The measurement of multidimensional poverty. Journal of Economic Inequality 1, 25-49.

Consejo Económico y Social (2013). Informe 03/2013 sobre distribución de la renta en España: desigualdad, cambios estructurales y ciclos. Madrid: CES.

Decancq, K., \& M. A. Lugo (2008): "Setting Weights in Multidimensional Indices of Wellbeing and Deprivation", OPHI Working Papers, $\mathrm{n}^{\circ}$ 18, Queen Elizabeth House, University of Oxford.

Desai, M., \& Shah, A. (1988). An econometric approach to the measurement of poverty. Oxford Economic Papers, 40(3), 505-522.

Duclos, J.-Y., Sahn, D.E.\& Younger, S. D. (2006). Robust Multidimensional Poverty Comparisons. Economic Journal, 116, 943-968. 
European Commission (2004). Joint report by the Commission and the Council on social inclusion: Office for Official Publications of the European Communities.

Foster (2007). A Report on Mexican Multidimensional Poverty Measurement. OPHI Working Paper, $n^{\circ} 40$.

Foster, J., Greer, J. \& Thorbecke, E. (1984). A Class of Decomposable Poverty Measures, Econometrica. 52(3), 761- 765.

Garroway, C., \& De Laiglesia, J. R. (2012). On the Relevance of Relative Poverty for Developing Countries, OECD Development Centre Working Papers 314, OECD Publishing.

Gordon, D., Nandy, S., Pantazis, C., Pemberton, S. \& Townsend, P. (2003). Child Poverty in the Developing World, Policy Press: Bristol.

Guio, A.C., Fusco, A. \& Marlier, E. (2009). An European Union Approach to Material Deprivation using EU-SILC and Eurobarometer data. IRISS Working Paper 2009-19, CEPS/INSTEAD, Differdange, Luxembourg.

Jenkins, S. P, \& Lambert, P.J. (1997). Three i's of poverty curves, with an analysis of UK poverty trends. Oxford Economic Papers, 49, 317-327.

Lasso de la Vega, C. (2010). Counting poverty orderings and deprivation curves. In: Bishop, J.A. (Ed.), Studies in Applied Welfare Analysis: Papers from the Third ECINEQ Meeting, Research on Economic Inequality, Volume 18, 153-172. Emerald Group Publishing Limited, Bingley.

Lemmi, A., \& Betti, G. (2006). Fuzzy Set Approach to Multidimensional Poverty Measurement. Economic Studies in Inequality, Social Exclusion and Well-being. Springer, New York.

Peña, D. (2002). Análisis de datos multivariantes, McGraw Hill.

Ravallion, M., \& Chen, S. (2011). Weakly Relative Poverty. The Review of Economics and Statistics, 93(4), 1251-1261.

Sen, A. (1983). Poverty, Relatively Speaking. Oxford Economic Papers, 44, 153-169.

Sen, A. K. (1985). Commodities and Capabilities, Amsterdam, Elsevier.

Sen, A. K. (2000). Social exclusion: Concept, application, and scrutiny ( $\left.\mathrm{n}^{\mathrm{o}} 1\right)$. Manila: Office of Environment and Social Development, Asian Development Bank.

Sen, A. (2006). Conceptualizing and measuring poverty. Poverty and inequality, 30-46.

Silber, J. (2007). Measuring poverty: taking a multidimensional perspective. Hacienda Pública Española, 182(3), 29-74.

Townsend, P (1979), Poverty in the United Kingdom, Harmondsworth, Penguin.

Tukey, J.W. (1977). Exploratory data analysis. Addison-Wesley Publishing Co.

Ura, K., Alkire, S., Zangmo, T. \& Wangdi, K. (2012). An extensive analysis of the gross national happiness index. Centre of Bhutan Studies.

Whelan, C., \& B. Maître (2012). Understanding material deprivation in Europe: a multilevel analysis. Research in Social Stratification and Mobility, 30, 489-503. 
Whelan, C., \& B. Maître (2013). Material Deprivation, Economic Stress and Referencing Groups in Europe: An Analysis of EU-SILC 2009. European Sociological Review, 29(6). 